\title{
The study of polluted water control engineering course reform in local universities
}

\author{
Xue $\mathrm{Li}^{1, \mathrm{a}}$, Shiying Zhang ${ }^{1, \mathrm{~b}^{\star}}, \mathrm{Fei}_{\mathrm{Li}} \mathrm{i}^{2, \mathrm{c}}$, Min Ruan ${ }^{3, \mathrm{~d}}$, Xingsheng Liao ${ }^{1, \mathrm{e}}$, \\ ${ }^{1}$ School of Biological and Environmental Engineering, Changsha University, Changsha 410022, \\ China \\ ${ }^{2}$ School of Information and Safety Engineering, Zhongnan University of Economics and Law, \\ Wuhan 430073, China \\ ${ }^{3}$ School of Energy and Power Engineering, Changsha University of Science \& Technology, \\ Changsha 410076, China \\ agina0131@163.com, b13875852619@163.com, clifei@znufe.edu.cn, dmaggie_rm@163.com \\ e531866837@qq.com
}

Keywords: local universities, polluted water control engineering, course reform

\begin{abstract}
In order to comply with the new requirement of personnel training and the transformation of local universities to applied technological universities, this article associate with the teaching practice of Changsha University, aims at promoting teaching reform through updating teaching methods, strengthening practical teaching, changing testing methods. All of the reforms successfully mobilized the enthusiasm and initiative of the students, and obtained the preliminary results.
\end{abstract}

\section{Introduction}

According to the statistical results, there are nearly 1055 local universities facing the problems of the low rate and the poor quality of employment, because of the unsuitable positioning. Therefore, the transformation of local universities to applied technological universities is regarded as the key point to solve the problem about universities structure adjustment.

By the end of April 2014, the Ministry of education held the first "International Forum on Industry \& Education" in Zhumadian, Henan. The most important issue of this conference is "how to construct the University of Applied Sciences within Chinese model" [1]. The transformation of local universities quickly became one of the most important problems of the education reform. As the main course of environmental engineering, water pollution control engineering teaching still use some traditional methods which can't arouse students' interest and far away from the practice. Therefore, in view of the current teaching situation of "polluted water control project", combined with the author's many years as the teaching experience of "polluted water control engineering" course in Changsha University, the problems and proposed some reform measures were investigated in this paper.

\section{Current situations of course teaching and existing problems}

Single teaching model and monotonous teaching content. The characteristics of "polluted water control project" are multi-disciplines and strong applicability. Therefore, it is difficult to make students have a better understanding of "polluted water control project" only by the traditional "Duck-stuffing" type of teaching. Though the traditional "Duck-stuffing” model of teaching causes the highly efficient teaching process, it is a fact that results in a lack of effective two-way communication, initiative, cooperation and creativity and so on [2].

There are quiet a number of teaching content needs to be associated with the practical application. However, most of the teachers lack of practical production experience, and they can't explain process flow or equipment of wastewater treatment in details. Therefore, it is difficult for students to have interest in exploring and studying the technological parameters of sewage treatment equipment. 
Focus more on theory teaching rather than practice. The existing major training program divides 7 semesters for theory, but only left 1 semester for graduation internship and dissertation. That's the fundamental reason cause the phenomenon that both the teacher and the student focus more on theory teaching rather than practice [3]. In addition, the positions of environmental management and monitoring are high professional request. Cooperation between schools and most of the enterprises is restricted to visiting internship, and students can't operate the machine by themselves. Therefore, the experience of progress design and machine operation is really limited for the local university students.

Course current assessment results deviate from the original intention. The designed aim of "polluted water" test is supervising and urging the students to master the relevant knowledge of polluted water treatment and control the basic skills of operation the polluted water treatment machine. However, because the depth of test content is limited, most of the students only prepare recitation topics by rote. The phenomenon deeply hinders the development of students' practical application ability [4].

\section{Reform measures of curriculum system}

According to the current situations and the existing problems, there are 3 measures proposed in the following.

Combining research-and-discussion teaching with practice. Research-and-discussion teaching is a kind of teaching method that focus on problem solving. Teachers create a problem situation and students find the most effective way to solve the problem through searching, reading, analyzing, inducing, and discussing [5]. We have done a teaching experiment of the course of activated sludge method. The total teaching hours of this course were 12 class hours, and were divided into 3 parts.

In the first part, teachers used 8-9 hours introducing the flow, principle, design and calculation method of activated sludge process, especially the different means of removing nitrogen and phosphorus.

Secondly, 62 students were divided into 6 groups (every group had a team leader who has higher learning initiative and better academic performance), and were sent to 3 domestic sewage treatment plants (MSBR, Carrousel oxidation ditch and CASS Technology, respectively) by turns. Every group has a 2 week internship for visiting and learning about the process flow, the import and export water quality indicators, the biochemical reaction pool structure, the main equipment, the sewage pipe sludge pipeline and gas pipeline layout, some design parameters of the secondary clarifier, and the treatment of excess sludge, following the experienced engineers.

In the last part, all of the groups collected and collated their photos and notes, which were taken during the internship, and made a final presentation with PowerPoint in the last class. Every group had 12-15 minutes to show their achievements and teacher used 2-3 minutes to comment and summarize.

This teaching experiment was both used in the grades of 2012 and 2013 students, and all received stronger-than-expected results. This internship in the domestic sewage treatment plants commendably filled the blank of CASS and MSBR, which didn't be introduced well in the designated teaching material. This kind of teaching mode not only stimulated the students' learning enthusiasm, but also improved their presentation skills. Students also give a good feed back about this kind of teaching model. In the final assessment of teaching, this course teacher evaluation of teaching performance ranked third in the department.

Making full use of the school-enterprise-cooperation "Collaborative Innovation Center" platform, and inviting experienced engineer to the classroom. The "Environmental and energy photo catalysis Collaborative Innovation Center" platform was constructed by Changsha University and obtained the identification of cultivating units in 2015. During the process of construction, a number of environmental protection companies signed a depth of cooperation agreement with this platform.

Kaitian environmental technological company is one of the cooperative enterprises of this platform and some experienced engineers who have been worked in design Institute from Kaitian 
were invited to give some professional speech about this course, like the construction of the construction of sewage treatment plant. The experienced engineers used abundant practical cases instead the traditional theoretical teaching, which shown a strong interaction with students. Every student enjoyed a great benefit from this special class though the class is only 2 hours. The special time for Q\&A (questions and answers) successfully solved the problem that most of teachers are lack of practical experience and given a prefect model of how to design and calculate.

Reforming the examining method. Examining Method: Attendance, speak, homework, case analysis and other performance in class account for $30 \%$, and the final exam accounts for $70 \%$ in the hundred-mark system.

The examining method in the past includes class performance (accounts for 30\%) and final exam (accounts for 30\%), and the class performance includes attendance (accounts for 30\%) and homework (accounts for 70\%). The final course sores are mostly depends on the final exam sores. However, in the new test model, the proportion of final examination results will be reduced. The class performance will be divided into three parts, attendance (accounts for 30\%), homework (accounts for 20\%), and seminar learning (accounts for 50\%).

Oral test form will be added into the final test. Oral test requests students' face-to-face answer some basic conceptions/questions (like the ratio of BOD and COD in biochemical wastewater or the application of vortex grit chamber) of this course in a very short time, and will count for $10 \%$ of the final exam.

This kind of oral test well simulates the actual interview of the company, and it will be beneficial to the students' future job hunting. And the written examination will cancel the question types like conception explaining in corresponding, and increase the open comprehensive design calculation. All the necessary parameters will be given, so students needn't to remember them by rote.

Others. There are some key points needed to be highlight in the reform progress. (1) Teachers need to do more communicate with the relevant engineers in the enterprise. (2) Teachers need to prepare more before the course, and spend more time in consulting data, correcting students' presentation materials, and giving inductions during their internship. (3) The test method needs further completion, refinement, adaptation, and customization, to avoid students achieve high sores without efforts.

\section{Summary}

Through the teaching reform and unremitting efforts, the course of "polluted water control engineering" formed a set of original teaching system, which was selected as the "excellent quality courses” of Changsha University, gained employers' recognitions and resulted in good instruction effects. This is a wonderful turning point of the transformation of local universities to applied technological universities. However, the deeply reform of this course is a long-term and complex progress, involving course design, production practice, cognitive practice, and experimental teaching. Therefore, the deeply reform of this course needs to be continuously improved in the practice.

\section{Acknowledgments}

This study was financially supported by the Program for the National Natural Science Foundation of China (51308076, 51408206, 51578222); The Education Department of Hunan Province (Grant No. 13C1016)

*Corresponding author at: School of Biological and Environmental Engineering, Changsha University, Changsha 410022, China. Tel.: +86-731-84261421;

E-mail address: 13875852619@163.com (Shiying Zhang). 


\section{Reference}

[1] S.F. Hu, Q. Wang, J.J. Cheng, Exploration and Practice on the reform of curriculum evaluation of local application oriented Universities -- a case study of the University of Applied Technology in Germany, J. Journal of the National Institute of Education Administration. 1 (2006) 88-91.

[2] X.L. Zhou, C.Y. Hu, Discussion on teaching method of "polluted water control engineering", J. Education and Teaching Forum. 13 (2014) 92-93.

[3] B. Liu. The teaching method reform of "polluted water control engineering", J. Chemical industry in Shandong. 23 (2015) 130-131.

[4] F. Li, J. Zhang, D. Chen, Analytical Review of Current Doctor Cultivation in China, C. International Symposium on Social Science. 31 (2016)101-104.

[5]. Xu ML, Hu ZF. Application of seminar teaching method in "polluted water control project", J. Chemical industry in Guangdong. 6 (2016) 211-212. 